\title{
Mobilization of TLR4 Into Lipid Rafts by Aggregatibacter Actinomycetemcomitans in Gingival Epithelial Cells
}

\author{
Haruka Imai Tsuyoshi Fujita Mikihito Kajiya Kazuhisa Ouhara Tetsuya Yoshimoto \\ Shinji Matsuda Katsuhiro Takeda Hidemi Kurihara \\ Department of Periodontal Medicine, Division of Applied Life Science, Institute of Biomedical \& Health \\ Sciences, Hiroshima University, Hiroshima, Japan
}

\section{Key Words}

Lipid raft • Toll-tike receptor - Aggregatibacter actinomycetemcomitans • Gingival epithelial cells

\begin{abstract}
Background: An investigation of the mechanisms underlying the production of inflammatory cytokines through the stimulation of microorganisms on gingival epithelial cells may provide insights into the pathogenesis of the initiation of periodontitis. Lipid rafts, microdomains in the cell membrane, include a large number of receptors, and are centrally involved in signal transduction. We herein examined the involvement of lipid rafts in the expression of interleukin (IL-6) and IL-8 in gingival epithelial cells stimulated by periodontal pathogens. Methods: OBA9, a human gingival cell line, was stimulated by Aggregatibacter actinomycetemcomitans or tumor necrosis factor (TNF)- $\alpha$ in the presence of methyl- $\beta$-cyclodextrin (M $\beta C D)$. Results: A. actinomycetemcomitans or TNF- $\alpha$ increased IL- 8 and IL- 6 mRNA levels, and promoted the phosphorylation of ERK and p38 MAP kinase in OBA9. The pretreatment with M $\beta C D$ abolished increases in IL- 6 and IL- 8 mRNA levels and the phosphorylation induced by $A$. actinomycetemcomitans, but did not suppress the response induced by TNF- $\alpha$. The transfection of TLR4 inhibited A. actinomycetemcomitans-induced increases in IL-8 and IL- 6 mRNA levels. Confocal microscopy revealed that M $\beta C D$ inhibited the mobilization of TLR4 into lipid rafts. Conclusion: The mobilization of TLR4 into lipid rafts is involved in the expression of inflammatory cytokines and phosphorylation of MAP kinase in human gingival epithelial cells stimulated by $A$. actinomycetemcomitans.
\end{abstract}

\section{Introduction}

Periodontitis is a biofilm-associated inflammatory disease of the periodontium that is caused by a shift in the local ecology. The gingival epithelium is the first line of defense against a microbial challenge and plays a crucial role as a mechanical barrier to bacterial invasion and in innate immune responses to infectious inflammation in periodontal tissue 


\section{Cellular Physiology Cell Physiol Biochem 2016;39:1777-1786 \begin{tabular}{l|l|l|} 
and BOI: 10.1159/000447877 & $\begin{array}{l}\text { C) 2016 The Author(s). Published by S. Karger AG, Basel } \\
\text { www.karger.com/cpb }\end{array}$
\end{tabular} \\ Imai et al.: Lipid Rafts and TLR4 in A.actinomycetemcomitans-Stimulated Cells}

$[1,2]$. Therefore, an investigation of the interaction between the gingival epithelium and periodontopathic bacteria may provide insights into the pathogenesis of the initiation of periodontitis.

Interleukin (IL)-8 and IL-6 are well-known inflammatory cytokines and are present in diseased human periodontal tissues [3-7]. IL-8 levels in periodontal tissue and gingival crevicular fluid have been correlated with disease severity [8]. Furthermore, the expression of IL-8 in diseased tissue, particularly in the gingival epithelium, has been correlated with the migration of polymorphonuclear leukocytes [3, 9-11]. IL-6 is produced by several cell types, such as B and T lymphocytes, monocytes, fibroblasts, and epithelial cells, and is a major mediator of host responses to tissue injury and infection [12]. Therefore, elucidating the mechanisms underlying the production of IL- 6 and IL-8 in gingival epithelial cells in the response to periodontal pathogens may contribute to a better understanding of the initiation of periodontitis. Strategies that modulate the production of IL- 6 and IL-8 by gingival epithelial cells may be applicable to the treatment or prevention of periodontitis. Based on this hypothesis, we previously reported that irsogladine maleate, an anti-gastric ulcer agent, effectively prevented periodontitis by regulating the expression of IL- 8 and IL- 6 in gingival epithelial cells $[13,14]$.

Similar to this concept, we recently demonstrated that the anti-fungal drug, amphotericin B down-regulated the Aggregatibacter actinomycetemcomitans-induced production of IL-8 and IL-6 in human gingival epithelial cells [15]. Since amphotericin B binds to cholesterol in mammalian cell membranes [16, 17], cholesterol may be involved in the regulation of inflammatory mediators. Lipid rafts are unique biophysical entities enriched in glycosphingolipids, cholesterol, and sphingomyelin, and function as platforms in protein sorting and signal transduction [18]. Therefore, lipid rafts play roles in innate immunity on the gingival epithelium such as the activation of toll-like receptors. Previous studies showed that TLR4 is expressed in gingival epithelial cells and is involved in enhancing the expression of IL-6 and IL-8 [19-21]. Therefore, we herein investigated the roles of lipid rafts and TLR4 on the expression of IL-8 and IL- 6 in gingival epithelial cells stimulated with A. actinomycetemcomitans.

\section{Materials and Methods}

\section{Reagents and antibodies}

M $\beta C D$ was purchased from Sigma-Aldrich (St Louis, MO, USA). TNF- $\alpha$ was purchased from R\&D Systems (Minneapolis, MN, USA). Porphyromonas gingivalis-LPS and Escherichia coli-LPS were purchased from InVivoGen (San Diego, CA, USA). Humedia-KB2 medium was obtained from Kurabo (Osaka, Japan). Todd-Hewitt broth was obtained from BBL $^{\mathrm{R}}$ (Cockeysville, MD, USA). Yeast extract was from Difco Laboratories (Detroit, MI, USA). SB203580 and PD98059 were purchased from Calbiochem (La Jolla, CA, USA). ISOGEN was from Wako Pure Chemical Industries (Osaka, Japan). A rabbit anti-phosphorylated p38 MAP kinase antibody, rabbit anti-total p38 MAP kinase antibody, rabbit anti-phosphorylated ERK antibody, and rabbit anti-total ERK antibody were from Cell Signaling (Beverly, MA, USA). A mouse anti-human TLR4 antibody was obtained from IMGENEX (San Diego, CA, USA). Alexa Fluor488 conjugates of Cholera toxin subunit B (CT-B) were obtained from Thermo Fisher Scientific (Waltham, MA, USA). HRP-conjugated sheep anti-rabbit IgG or anti-mouse IgG and ECL Prime Western blotting detection reagents were obtained from Amersham Biosciences (Arlington Heights, IL, USA).

Culture of A. actinomycetemcomitans

A. actinomycetemcomitans Y4 (purchased from the American Type Culture Collection, Manassas, VA, USA) was grown in Todd-Hewitt broth supplemented with $1 \%$ yeast extract at $37^{\circ} \mathrm{C}$ for 2 days. Following their cultivation, whole cells were fixed with $1 \%$ formalin at $4^{\circ} \mathrm{C}$ for $12 \mathrm{~h}$, harvested by centrifugation, and washed three times in PBS (pH 7.4). A portion of washed A. actinomycetemcomitans was suspended in Humedia-KB2 medium ( $\mathrm{pH} 7.4$ ) containing $10 \mu \mathrm{g} / \mathrm{ml}$ insulin, $5 \mu \mathrm{g} / \mathrm{ml}$ transferrin, $10 \mu \mathrm{M} 2$-mercaptoethanol, $10 \mu \mathrm{M}$ 2-aminoethanol, and $10 \mathrm{nM}$ sodium selenite. 


\section{Cellular Physiology Cell Physiol Biochem 2016;39:1777-1786

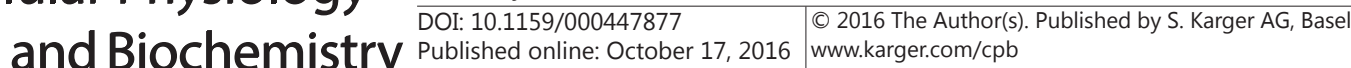 \\ Imai et al.: Lipid Rafts and TLR4 in A.actinomycetemcomitans-Stimulated Cells}

Cell culture

The SV40-antigen-immortalized gingival epithelial cell line, OBA9 was kindly provided by Dr. Shinya Murakami (Osaka University Graduate School of Dentistry, Osaka, Japan). OBA9 were seeded on $60-\mathrm{mm}$ plastic tissue culture plates and maintained in Humedia-KB2 medium containing 10 $\mathrm{g} / \mathrm{ml}$ insulin, $0.1 \mathrm{ng} / \mathrm{ml} \mathrm{hEGF}, 0.67 \mu \mathrm{g} / \mathrm{ml}$ hydrocortisone hemisuccinate, $50 \mu \mathrm{g} / \mathrm{ml}$ gentamycin, $0.4 \%$ BPE, and $50 \mathrm{ng} / \mathrm{ml}$ amphotericin $\mathrm{B}$ (medium $\mathrm{A}$ ) under $5 \% \mathrm{CO}_{2} / 95 \%$ air at $37^{\circ} \mathrm{C}$. When cells reached subconfluence, they were harvested and subcultured.

MTS cytotoxicity assay

The MTS assay was performed using the Cell Titer $96^{\mathrm{R}}$ One Solution Cell Proliferation Assay kit (Promega, Madison, WI). OBA9 were seeded on 96-well microtiter plates, and maintained in $100 \mu$ l of medium A. Confluent OBA9 were treated with $\mathrm{M} \beta C \mathrm{C}$ from $50 \mu \mathrm{M}$ to $10 \mathrm{mM}$ in Humedia-KB2 medium containing $10 \mu \mathrm{g} / \mathrm{ml}$ insulin, $0.1 \mathrm{ng} / \mathrm{ml} \mathrm{hEGF,} 0.67 \mu \mathrm{g} / \mathrm{ml}$ hydrocortisone hemisuccinate, $50 \mu \mathrm{g} / \mathrm{ml}$ gentamycin, and $50 \mathrm{ng} / \mathrm{ml}$ amphotericin B (medium B), and were then incubated at $37^{\circ} \mathrm{C}$ under $5 \% \mathrm{CO}_{2} / 95 \%$ air for $24 \mathrm{~h}$. Ten microliters of Cell Titer 96 Aqueous One Solution Reagent was added to the culture at the end of the incubation period. After a 2-h incubation, absorbance was measured using a reference wavelength of 490 nm.

\section{RNA preparation}

OBA9 were seeded at a density of $2 \times 10^{4}$ cells/35-mm plastic tissue culture plate, and maintained in 2 ml of medium A. SB203580 (p38 MAP kinase inhibitor) and PD98059 (ERK inhibitor) were used to examine the involvement of p38 MAP kinase and ERK on the expressions of IL-6 and IL-8. Confluent OBA9 were pretreated with M $\beta C D(0.1,0.5$, and $1 \mathrm{mM})$, SB203580 $(10 \mu \mathrm{M})$, and PD98059 $(10 \mu \mathrm{M})$ for $30 \mathrm{~min}$, and then exposed to formalin-killed A. actinomycetemcomitans $\mathrm{Y} 4$ at $1 \times 10^{8}$ cells $/ \mathrm{ml}$ or TNF- $\alpha(50 \mathrm{ng} / \mathrm{ml})$ for $12 \mathrm{~h}$ before the end of the incubation in $2 \mathrm{ml}$ of medium B. Total RNA was extracted using ISOGEN and quantified by spectrometry at 260 and $280 \mathrm{~nm}$.

\section{Measurement of IL-8 and IL-6 mRNA}

First-strand cDNA synthesis was performed with $1 \mu \mathrm{g}$ of the total RNA extract in a total volume of $10 \mu \mathrm{l}$ (Roche, Tokyo, Japan). Real-time PCR was performed with a LightCycler system using SYBR green (Roche). The sense and anti-sense primers used were as follows: IL-8, (sense) 5'-ATG ACT TCC AAG CTG GCC GTG GCT-3 and (anti-sense) 5'-TCT CAG CCC TCT TCA AAA ACT TCT C-3'; IL-6, (sense) 5'-ATG AAC TCC TTC TCC ACA AGC GC-3' and (anti-sense) 5'-GAA GAG CCC TCA GGC TGG ACT G-3'; and GAPDH (sense) 5'-AAC GTG TCA GTG GTG GAC CTG-3' and (anti-sense) 5'-AGT GGG TGT CGC TGT TGA AGT-3'.

Immunoblotting for phosphorylated p38 MAP kinase, total p38 MAP kinase, phosphorylated ERK, and total ERK

In order to detect phosphorylated p38 MAP kinase, total p38 MAP kinase, phosphorylated ERK, and total ERK, confluent OBA9 were exposed to A. actinomycetemcomitans Y4 or TNF- $\alpha$ in the presence or absence of M $\beta C D$ at $50 \mu \mathrm{M}$ for $30 \mathrm{~min}$. Cells were lysed in $200 \mu \mathrm{l}$ of SDS sample buffer ( $62.5 \mathrm{mM}$ Tris- $\mathrm{HCl}$, $2 \%$ SDS, 10\% glycerol, $50 \mathrm{mM}$ dithiothreitol, and $0.01 \%$ bromophenol blue). Samples were resolved on a 10\% SDS-polyacrylamide gel by electrophoresis under non-reducing conditions and electrophoretically transferred onto membranes (Bio-Rad Laboratories, Hercules, CA). The membranes were blocked with 5\% non-fat dried milk for $1 \mathrm{~h}$ and then reacted with the rabbit anti-phosphorylated-p38 MAP kinase antibody, rabbit anti-total p38 MAP kinase antibody, rabbit anti-phosphorylated ERK antibody, or rabbit anti-total ERK antibody overnight. The membrane was incubated with HRP-conjugated sheep anti-rabbit IgG in TBS at room temperature for $1 \mathrm{~h}$. Immunodetection was performed according to the manual supplied with the ECL Prime Western blotting detection reagents.

\section{Small interfering RNA (siRNA) knockdown of TLR4}

Validated TLR4 siRNA and negative-control siRNA were obtained from Invitrogen (Van Allen Way Carlsbad, CA). OBA9 were seeded at a density of $2.0 \times 10^{4}$ cells/6-well plastic culture plates and cultured in medium $\mathrm{A}$ at $37^{\circ} \mathrm{C}$ for $24 \mathrm{~h}$. Thirty nanomoles of TLR 4 siRNA and negative control siRNA were transfected into cells using Lipofectamine RNAiMAX reagent (Invitrogen), according to the manufacturer's instructions. Cells treated with or without stimulants were collected after a 48-h incubation. 


\section{Cellular Physiology Cell Physiol Biochem 2016;39:1777-1786 \\ \begin{tabular}{cc|cc} 
DOI: 10.1159/000447877 & O 2016 The Author(s). Published by S. Karger AG, Basel \\
and Biochemistry & Published online: October 17, 2016 kargercom/cpb
\end{tabular} \\ Imai et al.: Lipid Rafts and TLR4 in A.actinomycetemcomitans-Stimulated Cells}

Confocal immunofluorescence microscopy

Confluent OBA9 were exposed to A. actinomycetemcomitans Y4 in the presence or absence of MBCD at $50 \mu \mathrm{M}$ on 35-mm glass-bottomed dishes (IWAKI, Chiba, Japan), washed with PBS, and fixed with $4 \%$ paraformaldehyde in PBS. Non-specific binding was blocked by an incubation with TBS containing $0.2 \%$ casein and $0.1 \%$ Triton X-100 for 20 minutes. Cells were incubated with the mouse anti-human TLR4 antibody (1:200), cholera toxin subunit B (CT-B) Alexa Fluor 488 conjugates (1:200), and DAPI solution $(1: 200)$ at $4{ }^{\circ} \mathrm{C}$ overnight. After three washes with PBS for 5 minutes, the cells were incubated with Alexa Fluor 594 anti-mouse IgG antibody (Invitrogen; 1:200) at room temperature for $1 \mathrm{~h}$. After rinsing with PBS, fluorescence signals were detected with a Zeiss LSM 510 laser scanning confocal microscope (Zeiss MicroImaging, Inc., Thornwood, NY).

\section{Statistical analysis}

Comparisons between groups were performed using the Student's $t$-test.

\section{Results}

Effects of MBCD on IL-6 and IL-8 mRNA levels in OBA9 stimulated with A. actinomycetemcomitans or TNF- $\alpha$

The MTS assay was performed to determine the toxicity of M $\beta C D$. OBA9 were incubated with various concentrations of $M \beta C D$ for $24 \mathrm{~h}$. The MTS assay revealed that $M \beta C D$ at less than $2.5 \mathrm{mM}$ had a negligible effect on OBA9 viability. However, $\mathrm{M} \beta \mathrm{CD}$ at $5 \mathrm{mM}$ significantly decreased in viability (data not shown). $M \beta C D$ at $5 \mathrm{mM}$ markedly affected cell morphology, whereas concentrations less than $2.5 \mathrm{mM}$ did not (data not shown).

Real-time PCR was used to investigate the effects of M $\beta C D$ on A. actinomycetemcomitans-induced inflammatory mediators. M $\beta C D$ was added to the cell culture 30 min before the stimulation with A. actinomycetemcomitans. The exposure of OBA9 to

Fig. 1. Effects of $M \beta C D$ on IL-8 and IL-6 mRNA levels in OBA9 stimulated by $A$. actinomycetemcomitans or TNF- $\alpha$. (A, B) Confluent OBA9 were exposed to killed A actinomycetemcomitans at $1 \times 10^{8}$ cells $/ \mathrm{ml}$ in the presence or absence of M $\beta C D$ for $12 \mathrm{~h}$. (C, D) Confluent OBA9 were exposed to TNF- $\alpha$ at $50 \mathrm{ng} / \mathrm{ml}$ in the presence or absence of M $\beta C D$ for $12 \mathrm{~h}$. IL- 8 and IL-6 mRNA levels were analyzed by real-time PCR. Three independent experiments were performed and similar results were obtained. Values are means \pm SD of three wells in one experiment. ** Significantly different ( $t$-test, $\mathrm{P}<0.01) .{ }^{*}$ Significantly different (t-test, $\mathrm{P}<0.05)$.
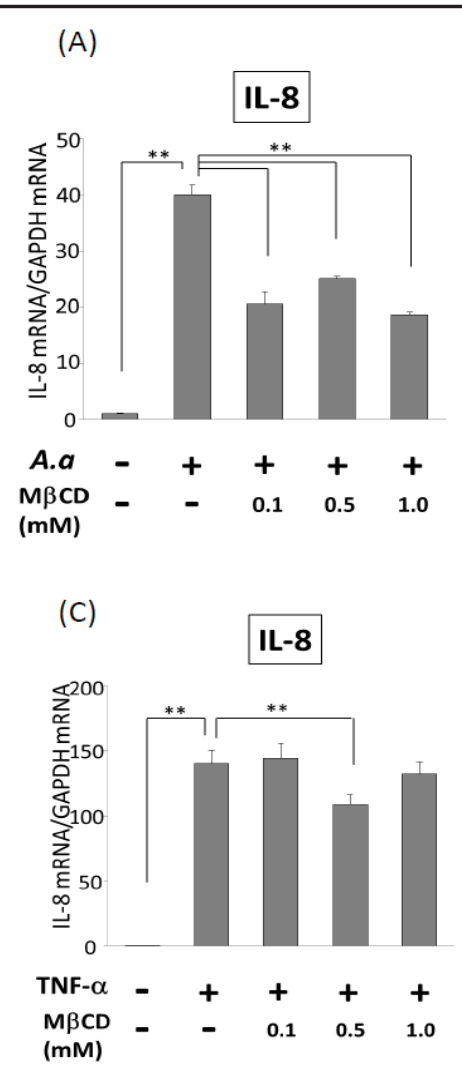

(B)

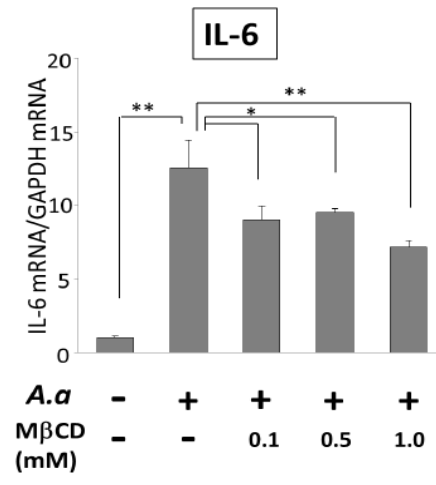

(D)

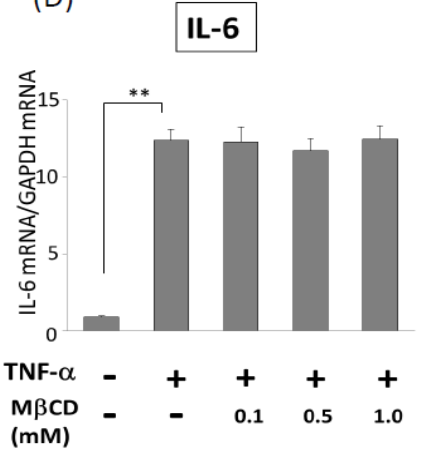


Fig. 2. Involvement of ERK and p38 MAP kinase in the M $\beta C D$-induced suppression of IL-8 and IL-6 in OBA9 stimulated by $A$. actinomycetemcomitans or TNF- $\alpha$. (A, B) Effects of M $\beta C D$ on $A$. actinomycetemcomitans- or TNF- $\alpha$-induced phosphorylation of ERK and p38 MAP kinase. Confluent OBA9 were exposed to A. actinomycetemcomitans at 1 $\times 10^{8}$ cells $/ \mathrm{ml}$ or TNF- $\alpha$ at $50 \mathrm{ng} / \mathrm{ml}$ in the presence or absence of $\mathrm{M} \beta C D$ before the end of the incubation. Phosphorylated ERK, total ERK, phosphorylated p38 MAP kinase, and total p38 MAP kinase were analyzed by Western blotting. The bands are representative of three independent experiments. (C, D) Effects of SB203580 or PD98059 on IL-8 and IL-6 mRNA levels in OBA9 exposed to killed A. actinomycetemcomitans. Confluent OBA9 were exposed to A actinomycetemcomitans at $1 \times 10^{8}$ cells $/ \mathrm{ml}$ in the presence or absence of SB203580 or PD98059. IL-8 and IL-6 mRNA levels were analyzed by real-time PCR. Three independent experiments were performed and similar results were obtained. Values are means \pm SD of three wells in one experiment. ** Significantly different ( $t$-test, $\mathrm{P}<0.01$ ).
(A)

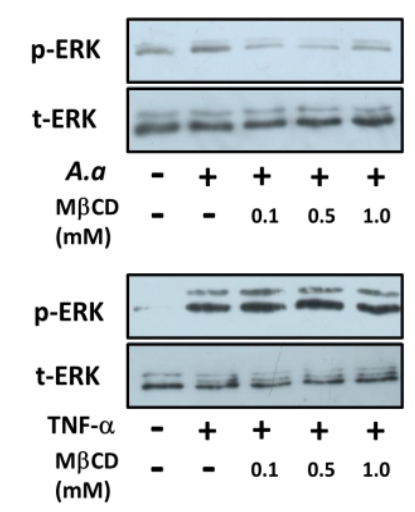

(C)

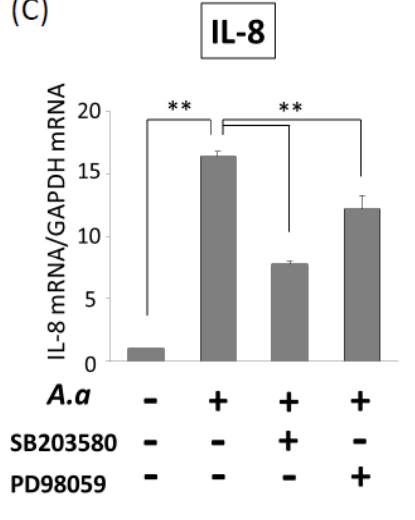

(B)

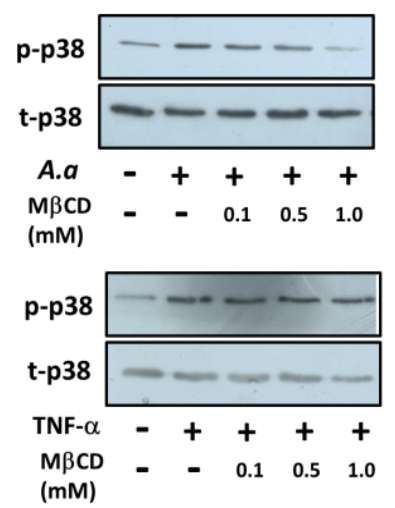

(D)

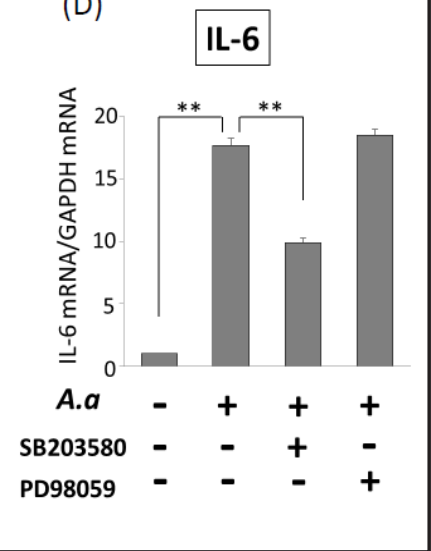

A. actinomycetemcomitans increased IL-6 and IL-8 mRNA levels. However, the addition of $\mathrm{M} \beta \mathrm{CD}$ to the culture significantly abolished $A$. actinomycetemcomitans-induced increases in these levels (Fig. 1). On the other hand, although TNF- $\alpha$ also increased the mRNA levels of IL-6 and IL-8 in OBA9, M $\beta$ CD had a negligible effect on TNF- $\alpha$-induced increases in IL- 6 and IL-8 (Fig. 1).

Since the phosphorylation of ERK and p38 MAP kinase is involved in the enhancement of IL- 6 and IL-8 levels in gingival epithelial cells, the effects of M $\beta C D$ on the A. actinomycetemcomitans- or TNF- $\alpha$-induced phosphorylation of ERK and p38 MAP kinase were examined. M $\beta C D$ attenuated the A. actinomycetemcomitans-induced phosphorylation of ERK and p38 MAP kinase in OBA9, but did not affect TNF- $\alpha$-induced phosphorylation. Furthermore, the pretreatment with SB203580 at $10 \mu \mathrm{M}$ for $30 \mathrm{~min}$ inhibited A. actinomycetemcomitans-induced increases in IL-8 and IL-6 mRNA levels in OBA9. PD98059 also attenuated the $A$. actinomycetemcomitans-induced increase in IL-8, but not in IL-6 levels in OBA9 (Fig. 2).

Involvement of TLR4 in the enhancement of IL-6 and IL-8 mRNA levels in OBA-9

In order to determine the involvement of TLR2 or TLR4 on A. actinomycetemcomitansinduced increases in IL-6 and IL-8 levels, $P$. gingivalis-LPS (TLR2 ligand) or E. coli-LPS (TLR4 ligand) was added to the culture in the presence or absence of M $\beta C D$. M $\beta C D$ did not influence the increases induced in IL-8 and IL-6 mRNA levels by P. gingivalis-LPS, whereas it suppressed those induced by $E$. coli-LPS. In addition, the transfection of TLR4 inhibited $A$. actinomycetemcomitans-induced increases in IL-8 and IL-6 mRNA levels (Fig. 3). 
Fig. 3. Involvement of TLR4 in the $\mathrm{M} \beta \mathrm{CD}$-induced suppression of IL-8 and IL-6 mRNA levels in OBA9 stimulated by $A$. actinomycetemcomitans. (A, B) Effects of M $\beta C D$ on IL-8 and IL-6 mRNA levels in OBA9 stimulated by $P$ gingivalis-LPS or $E$. coli-LPS. Confluent OBA9 were exposed to P. gingivalis-LPS or E. coli-LPS for $12 \mathrm{~h}$ in the presence or absence of M $\beta C D$. IL- 8 and IL- 6 mRNA levels were analyzed by real-time PCR. Three independent experiments were performed and similar results were obtained. Values are means \pm SD of three wells in one experiment. ** Significantly different ( $t$-test, $\mathrm{P}<0.01$ ). (C, D) Confluent OBA9 cells, having been transfected with the negative control (neg) or TLR4 siRNA, were exposed to A. actinomycetemcomitans for $12 \mathrm{~h}$. IL-8 and IL-6 mRNA levels were analyzed by real-time PCR.

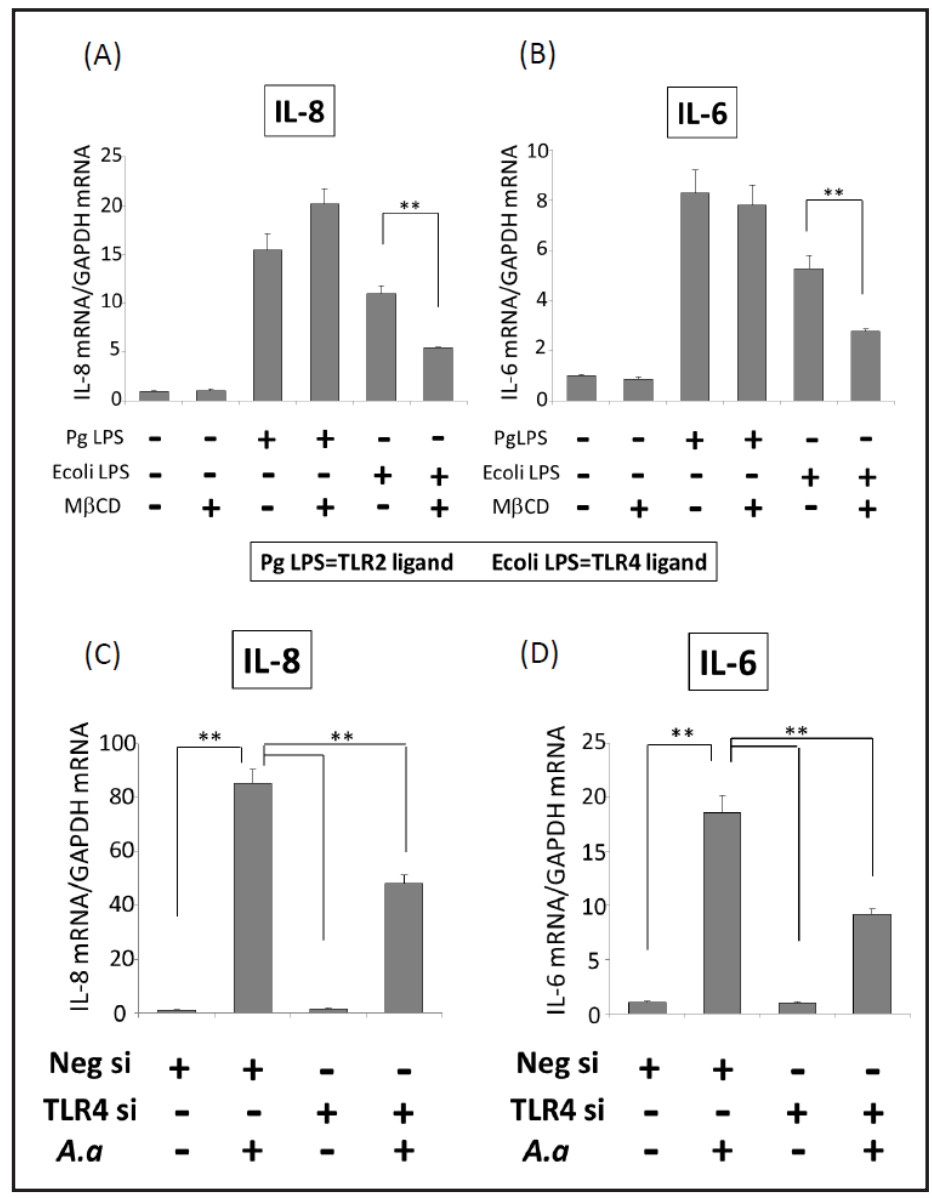

Involvement of TLR4 in A. actinomycetemcomitans-induced lipid rafts

Since the results of the present study suggest that reductions in IL-6 and IL-8 mRNA levels are medicated through TLR4, we investigated the involvement of TLR4 in $A$. actinomycetemcomitans-induced lipid rafts in OBA9 in more detail. Confocal microscopy showed that TLR was expressed apart from CT-B in non-stimulated cells. However, the co-localization of TLR4 and CT-B (pointed by arrows) was observed after a 5- or 15-min stimulation with $A$. actinomycetemcomitans (Fig. 4). Furthermore, M $\beta C D$ inhibited the colocalization of TLR4 and CT-B in OBA9 (Fig. 5A). In order to validate the co-localization procedure of TLR4 and CT-B on images of cells, Manders coefficient was calculated by an intensity correlation analysis of Alexa Fluor 594 and Alexa Fluor 488. The average of Manders coefficient for TLR 4 and CT-B is shown in Fig. 5B. The addition of M $\beta C D$ inhibited $A$. actinomycetemcomitans-induced increases in the co-localization of TLR4 and CT-B in OBA9.

\section{Discussion}

In the present study, we demonstrated that lipid rafts are involved in A. actinomycetemcomitans-induced increases in IL-6 and IL-8 levels in cultures of human gingival epithelial cells. Furthermore, the mobilization of TLR4 into lipid rafts by A. actinomycetemcomitans was involved in the increases observed in IL- 6 and IL-8 levels in human gingival epithelial cells. These results suggest that lipid rafts play a role in $A$. actinomycetemcomitans-induced increases in IL-6 and IL-8 levels in gingival epithelial cells through TLR4.

$\mathrm{M} \beta \mathrm{CD}$ treatments have previously been described as a rapid and efficient method for selectively removing cholesterol from the plasma membranes of cultured cells [22, 23], and $\mathrm{M} \beta \mathrm{CD}$ has been extensively used as a cholesterol-depleting reagent. Therefore, we utilized 


\section{Cellular Physiology Cell Physiol Biochem 2016;39:1777-1786 \begin{tabular}{ll|l} 
DOI: 10.1159/000447877 & $\begin{array}{l}\text { O 2016 The Author(s). Published by S. Karger AG, Basel } \\
\text { wwww.karger.com/cpb }\end{array}$
\end{tabular} \\ Imai et al.: Lipid Rafts and TLR4 in A.actinomycetemcomitans-Stimulated Cells}

Fig. 4. Lipid rafts and the expression of TLR4 in OBA9 stimulated by A. actinomycetemcomitans. Confluent OBA9 were exposed to $A$. actinomycetemcomitans for the indicated time on $35-\mathrm{mm}$ glass-bottomed dishes. TLR4, CT-B was detected with a Zeiss LSM 510 laser scanning confocal microscope. Nuclei were counterstained with DAPI. (Green: CT-B, TLR4: red, nuclei: blue, marge: yellow appearance).
Fig. 5. Effects of $M \beta C D$ on lipid rafts and the expression of TLR4 in OBA9 stimulated by $A$. actinomycetemcomitans. Confluent OBA9 were exposed to A. actinomycetemcomitans at $1 \times 10^{8}$ cells $/ \mathrm{ml}$ for $15 \mathrm{~min}$ in the presence or absence of $\mathrm{M} \beta \mathrm{CD}$ at $50 \mathrm{M}$ on 35-mm glass-bottomed dishes. (A) TLR4, CT-B was detected with a Zeiss LSM 510 laser scanning confocal microscope. Nuclei were counterstained with DAPI. (Green: CT-B, TLR4: red, nuclei: blue, marge: yellow appearance). (B) Manders coefficient was used to measure the co-localization procedure of TLR4 and CT-B on images of cells. Each symbol represents an individual cell; small horizontal black lines indicate the mean value. Data are from three independent experiments with approximately 10-15 cells total. ${ }^{* *}$ Significantly different (t-test, $\mathrm{P}<0.01)$.

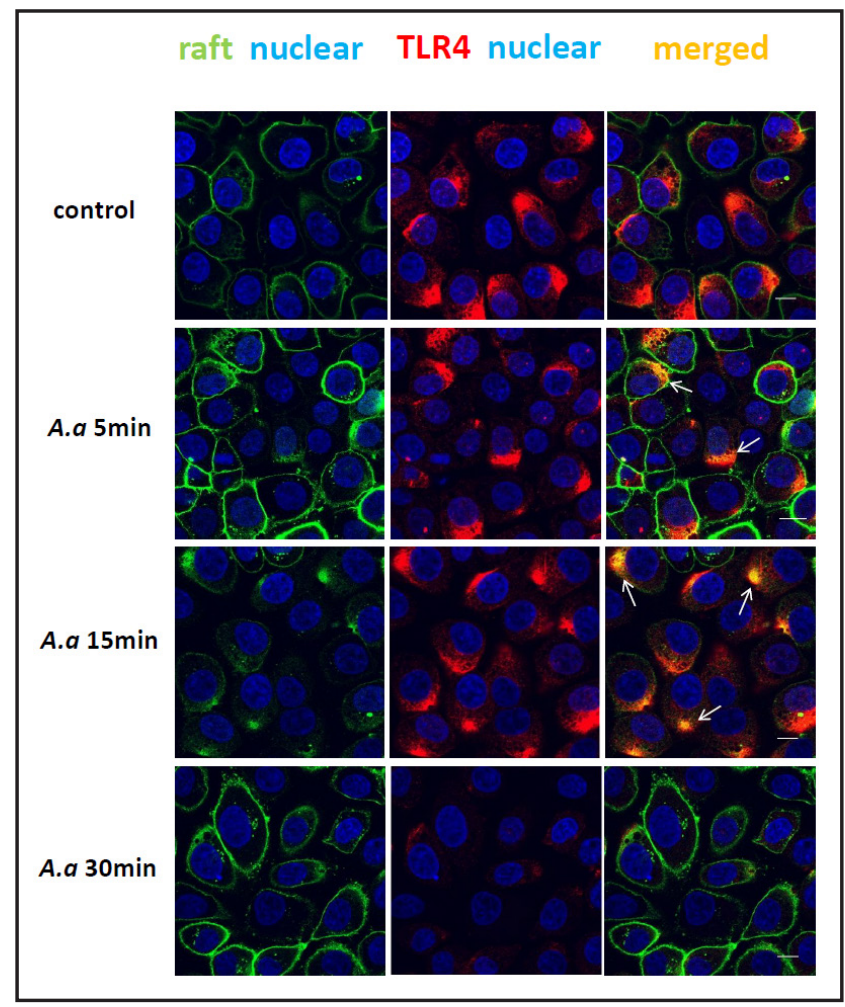

(A)

A.a Omin

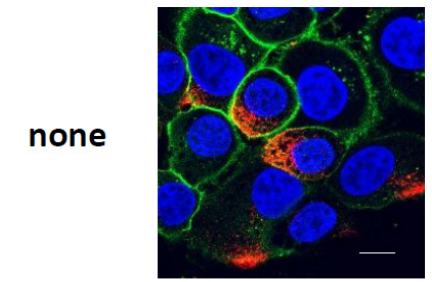

none

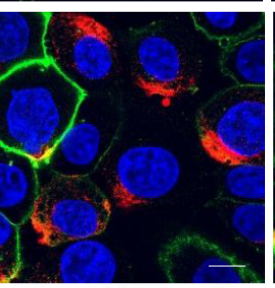

TLR4 raft nuclear

(B)

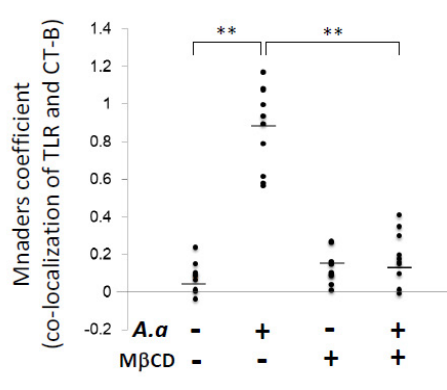

$\mathrm{M} \beta \mathrm{CD}$ in order to investigate whether the phosphorylation of MAP kinase and cytokine secretion induced by $A$. actinomycetemcomitans or TNF- $\alpha$ depends on plasma membrane cholesterol.Ourresultsindicated that $\mathrm{M} \beta \mathrm{CD}$ inhibited theincreasesintheproduction ofIL-8and 


\section{Cellular Physiology Cell Physiol Biochem 2016;39:1777-1786

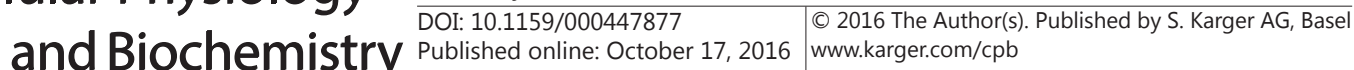 \\ Imai et al.: Lipid Rafts and TLR4 in A.actinomycetemcomitans-Stimulated Cells}

IL- 6 and phosphorylation of p38 MAP kinase and ERK induced by A. actinomycetemcomitans, but had a negligible effect on cytokine production and phosphorylation induced by TNF- $\alpha$. Our previous findings demonstrated that the phosphorylation of ERK and p38 MAP kinase is involved in the production of IL- 8 and IL-6, indicating that M $\beta C D$ acts upstream of MAP kinase in A. actinomycetemcomitans-stimulated cells. Furthermore, M $\beta C D$ suppressed increases in IL-6 and IL-8 levels induced by E. coli-LPS (TLR4 ligand), but not P. gingivalis LPS (TLR2 ligand). It also inhibited the A. actinomycetemcomitans-induced translocation of TLR4 into rafts. These results suggest that the translocation of TLR4 by A. actinomycetemcomitans is followed by the phosphorylation of p38 MAP kinase and ERK, and the translocation of the receptor into lipid rafts is a specific event for TLR4, but not for TNF- $\alpha$ receptors or TLR2 in human gingival epithelial cells.

The relationship between lipid rafts and TLR4 in inflammatory responses has been reported previously in several cell types. The depletion of cholesterol or disruption of lipid rafts by $\mathrm{M} \beta C D$ has been shown to down-regulate the TLR4-mediated inflammatory responses induced by E. coli-LPS [24-26]. In addition, M $\beta C D$ inhibited Helicobacter pylori-induced increases in the production of IL-8 by regulating the mobilization of TLR4 into lipid rafts in gastric epithelial cells [27]. Furthermore, the suppression of TLR4 recruitment into lipid rafts by surfactant lipid or ethanol caused a reduction in the LPS-induced cellular activation of macrophage-like cells and lung epithelial cells $[26,28]$. Thus, the molecules inhibiting the translocation of TLR4 may also result in the suppression of inflammatory responses in gingival epithelial cells. For example, glycyrrhizin has been shown to inhibit the LPS-induced translocation of TLR4 to lipid rafts, thereby attenuating LPS-mediated inflammatory responses [29]. Previous studies have shown that the accumulation of cholesterol in membranes is followed by the activation of downstream signaling events, such as MAP kinase and PI3 kinase. A treatment with M $\beta C D$ led to the selective attenuation of MAP kinase activation through ERK1/2 without affecting the translocation of TLR4 in macrophages [25]. On the other hand, the accumulation of free cholesterol in membranes activates TLR3 and TLR4 in addition to the sustained phosphorylation of p38 MAP kinase in macrophages [30]. This is consistent with the present results showing that $M \beta C D$ inhibited the phosphorylation of p38 MAP kinase and ERK in gingival epithelial cells. We previously reported that amphotericin, a cholesterol-binding agent, down-regulated A. actinomycetemcomitansinduced inflammatory responses by regulating MAP kinase signaling in gingival epithelial cells [15]. Therefore, amphotericin may also regulate TLR4-mediated MAP kinase signaling and inflammatory responses in gingival epithelial cells.

A recent study has indicated that CT-B binds to ganglioside GM1 and the removal of cholesterol does not influence binding to GM1 in Hela cells [31]. Therefore, changes in raft labeling after cholesterol extraction needed to be examined using other raft markers such as ostreolysin, which binds to membranes rich in cholesterol and sphingomyelin. Flotillin-1 and caveolin-1 are raft-associated transmembrane proteins that attach to two raft components and are co-distributed with ostreolysin [32]. Therefore, we performed double immunostaining of TLR4 and flotillin-1 or caveolin-1 in OBA9. The single staining of flotillin-1 or caveolin-1 was obtained, similar to CT-B in OBA9, but it was not possible to obtain merged images (unpublished data).

In the present study, we indicated that lipid rafts are involved in inflammatory responses in gingival epithelial cells stimulated by A. actinomycetemcomitans. Previous studies demonstrated that lipid rafts play a role in the regulation of cellular function in epithelial cells, such as the epithelial barrier or bacterial invasion [33-35]. Collectively, previous findings and the results of the present study indicate that $A$. actinomycetemcomitans-induced alternations in lipid rafts are involved in the weakening of the gingival epithelial barrier or bacterial invasion. Further studies on the mechanisms underlying innate cellular responses against periodontopathic bacteria may lead to treatments for or the prevention of periodontal disease. The results of the present study suggest that the regulation of cholesterol represents a novel method for suppressing inflammatory cytokines. 


\section{Cellular Physiology Cell Physiol Biochem 2016;39:1777-1786

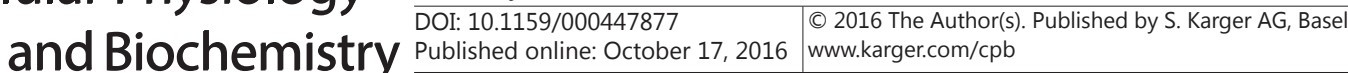 \\ Imai et al.: Lipid Rafts and TLR4 in A.actinomycetemcomitans-Stimulated Cells}

\section{Acknowledgments}

We thank Professor Shinya Murakami (Osaka University) for providing the OBA9 cell line. This study was supported in part by a Grant-in-Aid for Scientific Research (C) (No.24593123) from the Japan Society for the Promotion of Science, Japan.

\section{Disclosure Statement}

No potential conflicts of interest are disclosed.

\section{References}

1 Bosshardt DD, Lang NP: The junctional epithelium: From health to disease. J Dent Res 2005;84:9-20.

2 Shimono M, Ishikawa T, Enokiya Y, Muramatsu T, Matsuzaka K, Inoue T, Abiko Y, Yamaza T, Kido MA, Tanaka T, Hashimoto S: Biological characteristics of the junctional epithelium. J Electron Microsc (Tokyo) 2003;52:627-639.

3 Tonetti MS, Imboden MA, Gerber L, Lang NP, Laissue J, Mueller C: Localized expression of mrna for phagocyte-specific chemotactic cytokines in human periodontal infections. Infect Immun 1994;62:40054014.

4 Gamonal J, Acevedo A, Bascones A, Jorge 0, Silva A: Characterization of cellular infiltrate, detection of chemokine receptor ccr5 and interleukin-8 and rantes chemokines in adult periodontitis. J Periodontal Res 2001;36:194-203.

5 Garlet GP, Martins W, Ferreira BR, Milanezi CM, Silva JS: Patterns of chemokines and chemokine receptors expression in different forms of human periodontal disease. J Periodontal Res 2003;38:210-217.

6 Silva TA, Garlet GP, Fukada SY, Silva JS, Cunha FQ: Chemokines in oral inflammatory diseases: Apical periodontitis and periodontal disease. J Dent Res 2007;86:306-319.

7 Giannopoulou C, Kamma JJ, Mombelli A: Effect of inflammation, smoking and stress on gingival crevicular fluid cytokine level. J Clin Periodontol 2003;30:145-153.

8 Tsai CC, Ho YP, Chen CC: Levels of interleukin-1 beta and interleukin-8 in gingival crevicular fluids in adult periodontitis. J Periodontol 1995;66:852-859.

9 Fitzgerald JE, Kreutzer DL: Localization of interleukin-8 in human gingival tissues. Oral Microbiol Immunol 1995;10:297-303.

10 Garlet GP, Avila-Campos MJ, Milanezi CM, Ferreira BR, Silva JS: Actinobacillus actinomycetemcomitansinduced periodontal disease in mice: Patterns of cytokine, chemokine, and chemokine receptor expression and leukocyte migration. Microbes Infect 2005;7:738-747.

11 Miyauchi M, Kitagawa S, Hiraoka M, Saito A, Sato S, Kudo Y, Ogawa I, Takata T: Immunolocalization of cxc chemokine and recruitment of polymorphonuclear leukocytes in the rat molar periodontal tissue after topical application of lipopolysaccharide. Histochem Cell Biol 2004;121:291-297.

12 Kono Y, Beagley KW, Fujihashi K, McGhee JR, Taga T, Hirano T, Kishimoto T, Kiyono H: Cytokine regulation of localized inflammation. Induction of activated b cells and il-6-mediated polyclonal igg and iga synthesis in inflamed human gingiva. J Immunol 1991;146:1812-1821.

13 Fujita T, Kishimoto A, Shiba H, Hayashida K, Kajiya M, Uchida Y, Matsuda S, Takeda K, Ouhara K, Kawaguchi H, Abiko Y, Kurihara H: Irsogladine maleate regulates neutrophil migration and e-cadherin expression in gingival epithelium stimulated by aggregatibacter actinomycetemcomitans. Biochem Pharmacol 2010;79:1496-1505.

14 Miyagawa T, Fujita T, Ouhara K, Matsuda S, Kajiya M, Hayashida K, Imai H, Yoshimoto T, Iwata T, Shiba $\mathrm{H}$, Abiko Y, Kurihara H: Irsogladine maleate regulates the inflammatory related genes in human gingival epithelial cells stimulated by aggregatibacter actinomycetemcomitans. Int Immunopharmacol 2013;15:340-347.

15 Imai H, Fujita T, Kajiya M, Ouhara K, Miyagawa T, Matsuda S, Shiba H, Kurihara H: Amphotericin b downregulates aggregatibacter actinomycetemcomitans-induced production of il-8 and il-6 in human gingival epithelial cells. Cell Immunol 2014;290:201-208. 


\section{Cellular Physiology Cell Physiol Biochem 2016;39:1777-1786 \begin{tabular}{l|l|l|}
\hline DOI: 10.1159/000447877 & $\begin{array}{l}\text { C) 2016 The Author(s). Published by S. Karger AG, Basel } \\
\text { www.karger.com/cpb }\end{array}$
\end{tabular} \\ Imai et al.: Lipid Rafts and TLR4 in A.actinomycetemcomitans-Stimulated Cells}

16 Gray KC, Palacios DS, Dailey I, Endo MM, Uno BE, Wilcock BC, Burke MD: Amphotericin primarily kills yeast by simply binding ergosterol. Proc Natl Acad Sci U S A 2012;109:2234-2239.

17 Wilcock BC, Endo MM, Uno BE, Burke MD: C2'-oh of amphotericin b plays an important role in binding the primary sterol of human cells but not yeast cells. J Am Chem Soc 2013;135:8488-8491.

18 Simons K, Ikonen E: Functional rafts in cell membranes. Nature 1997;387:569-572.

19 Eskan MA, Benakanakere MR, Rose BG, Zhang P, Zhao J, Stathopoulou P, Fujioka D, Kinane DF: Interleukin1 beta modulates proinflammatory cytokine production in human epithelial cells. Infect Immun 2008;76:2080-2089.

20 Zhen L, Fan DS, Zhang Y, Cao XM, Wang LM: Resveratrol ameliorates experimental periodontitis in diabetic mice through negative regulation of tlr4 signaling. Acta Pharmacol Sin 2015;36:221-228.

21 Eskan MA, Rose BG, Benakanakere MR, Zeng Q Fujioka D, Martin MH, Lee MJ, Kinane DF: Tlr4 and s1p receptors cooperate to enhance inflammatory cytokine production in human gingival epithelial cells. Eur J Immunol 2008;38:1138-1147.

22 Klein U, Gimpl G, Fahrenholz F: Alteration of the myometrial plasma membrane cholesterol content with beta-cyclodextrin modulates the binding affinity of the oxytocin receptor. Biochemistry 1995;34:1378413793.

23 Hansen GH, Niels-Christiansen LL, Thorsen E, Immerdal L, Danielsen EM: Cholesterol depletion of enterocytes. Effect on the golgi complex and apical membrane trafficking. J Biol Chem 2000;275:51365142.

24 Triantafilou M, Miyake K, Golenbock DT, Triantafilou K: Mediators of innate immune recognition of bacteria concentrate in lipid rafts and facilitate lipopolysaccharide-induced cell activation. J Cell Sci 2002;115:2603-2611.

25 Cuschieri J: Implications of lipid raft disintegration: Enhanced anti-inflammatory macrophage phenotype. Surgery 2004;136:169-175.

26 Dai Q Zhang J, Pruett SB: Ethanol alters cellular activation and cd14 partitioning in lipid rafts. Biochem Biophys Res Commun 2005;332:37-42.

27 Lu DY, Chen HC, Yang MS, Hsu YM, Lin HJ, Tang CH, Lee CH, Lai CK, Lin CJ, Shyu WC, Lin FY, Lai CH: Ceramide and toll-like receptor 4 are mobilized into membrane rafts in response to helicobacter pylori infection in gastric epithelial cells. Infect Immun 2012;80:1823-1833.

28 Abate W, Alghaithy AA, Parton J, Jones KP, Jackson SK: Surfactant lipids regulate lps-induced interleukin-8 production in a549 lung epithelial cells by inhibiting translocation of tlr4 into lipid raft domains. J Lipid Res 2010;51:334-344.

29 Fu Y, Zhou E, Wei Z, Song X, Liu Z, Wang T, Wang W, Zhang N, Liu G, Yang Z: Glycyrrhizin inhibits lipopolysaccharide-induced inflammatory response by reducing tlr4 recruitment into lipid rafts in raw264.7 cells. Biochim Biophys Acta 2014;1840:1755-1764.

30 Sun Y, Ishibashi M, Seimon T, Lee M, Sharma SM, Fitzgerald KA, Samokhin AO, Wang Y, Sayers S, Aikawa M, Jerome WG, Ostrowski MC, Bromme D, Libby P, Tabas IA, Welch CL, Tall AR: Free cholesterol accumulation in macrophage membranes activates toll-like receptors and p38 mitogen-activated protein kinase and induces cathepsin k. Circ Res 2009;104:455-465.

31 Ermolinsky B, Peredelchuk M, Provenzano D: A-cyclodextrin decreases cholera toxin binding to gm1gangliosides. J Med Microbiol 2013;62:1011-1014.

32 Skočaj M, Resnik N, Grundner M, Ota K, Rojko N, Hodnik V, Anderluh G, Sobota A, Maček P, Veranič P, Sepčić K: Tracking cholesterol/sphingomyelin-rich membrane domains with the ostreolysin a-mcherry protein. PLoS One 2014;9:e92783.

33 Resnik N, Sepcic K, Plemenitas A, Windoffer R, Leube R, Veranic P: Desmosome assembly and cell-cell adhesion are membrane raft-dependent processes. J Biol Chem 2011;286:1499-1507.

34 Saito A, Kokubu E, Inagaki S, Imamura K, Kita D, Lamont RJ, Ishihara K: Porphyromonas gingivalis entry into gingival epithelial cells modulated by fusobacterium nucleatum is dependent on lipid rafts. Microb Pathog 2012;53:234-242.

35 Bowie RV, Donatello S, Lyes C, Owens MB, Babina IS, Hudson L, Walsh SV, O'Donoghue DP, Amu S, Barry SP, Fallon PG, Hopkins AM: Lipid rafts are disrupted in mildly inflamed intestinal microenvironments without overt disruption of the epithelial barrier. Am J Physiol Gastrointest Liver Physiol 2012;302:G781-793. 